4. Mohammad M, Ahamad F, Rahman SZ, Gupta V, Salman T. Knowledge attributes and practices of bioethics among doctors in Tertiary care government teaching hospital in India.J Clinic Res Bioeth. 2011;2:118-20.

5. Janakiram C, Gardens S. Knowledge, attributes and practice related to healthcare ethics among medical and dental postgraduate students in south India. Indian J Med Ethics. 2014 Apr-Jun; 11(2):99-104.

6. Singh S, Sharma PK, Bhandari B, Kaur R. Knowledge, awareness and practice ofethics among doctors in tertiary care hospital. Indian $J$ Pharmacol 2016;48:89-93.

7. Brogen SA, Rajkumari B, Laishram J, Joy A. Knowledge and Attitude of Doctors on Medical Ethics in Teaching Hospital Manipur. Indian J Med Ethics 2009;6(4):194-7.

8. Chopra M, Bharadwaj A, Mithra P, Singh A, Siddiqui A, Rajesh PR. Current status of Knowledge, attitude and practices towards healthcare ethics among doctors and nurses from North India - A multicenter study. JKIMSU. 2013 Jul-Dec;2(2):102-7.

\section{Age-based discrimination in Covid-19 patient care}

\section{Published online on July 7, 2020. DOI: 10.20529/IJME.2020.074}

Although all age groups are at risk of contracting Covid-19 disease, older people are facing the highest risk due to ageing and underlying health conditions (1). According to the US Centers for Disease Control and Prevention report, 8 out of 10 deaths reported in the US have been of adults 65 years old and older (2). Therefore, the global recommendation for older populations includes social isolation, which involves staying at home and avoiding contact with other people, possibly for an extended period of up to three or four months (3). Such distancing presents serious challenges to the health and wellbeing of older adults, more so those who are frail or have multiple chronic conditions (4).

The elderly are among the primary recipients of healthcare and require high-quality, specialised care (5); hence it must be considered how the Covid-19 pandemic and steps taken by governments, such as lockdown, affect their human rights (6). In some areas, Covid-19 is overwhelming intensive care unit beds, mechanical ventilator capacity, and the ability of hospital personnel to care for patients. There are also several reported cases of discrimination against and neglect of the elderly, due to negative attitudes that should be combated (7). The exclusion of older persons from medical treatments has been studied, but without considering the drastic health consequences for them (8).

Ageism is defined as a systematic stereotyping of and discrimination against people who are aged. Ageism and discriminatory practices toward the elderly are prevalent not only in the general population but also among healthcare personnel, especially those in long-term care programmes for the elderly (5). Inadequate training of health service providers for the aged leads to negative attitudes, and consequently, to adverse effects on healthcare outcomes (9). Aronson also points out that "internalised ageism may be strengthened because some older adults themselves have resisted identifying as at-risk. After all, it means they are acknowledging the reality of their age" (10).

Older adults should have the same protections as other age groups, and these must be adequately implemented, especially during the pandemic. Older people are more vulnerable and less equipped to defend themselves and to be assertive in demanding optimal medical care. Given the extent of ageist attitudes and stereotypes and the negative consequences of ageism for health and quality of care, developing effective educational interventions to sensitise both healthcare workers and the general population to ageism should be a priority.

Vahid Rashedi, Assistant Professor, School of Behavioral Sciences and Mental Health (Tehran Institute of Psychiatry), Iran University of Medical Sciences, Tehran, IRAN; Vahidreza Borhaninejad Assistant Professor (corresponding author - v.borhaninejad@kmu. ac.ir), Social Determinants of Health Research Center, Institute for Futures Studies in Health, Kerman University of Medical Sciences, Kerman, IRAN

\section{References}

1. World Health Organization. Supporting older people during the COVID-19 pandemic is everyone's business 2020 Apr 2[cited 2020 June 4]. Available from: https://www.euro.who.int/en/health-topics/healthemergencies/coronavirus-covid-19/news/news/2020/4/supportingolder-people-during-the-covid-19-pandemic-is-everyones-business

2. US Centers for Disease Control and Prevention. People who are at higher risk for severe illness. 2020 [Available from: https://www.cdc. gov/coronavirus/2019-ncov/need-extra-precautions/older-adults.html.

3. Brooke J, Jackson D. Older people and COVID-19: Isolation, risk and ageism. Journal of Clinical Nursing. 2020.

4. Steinman MA, Perry L, Perissinotto CM. Meeting the care needs of older adults isolated at home during the COVID-19 pandemic. JAMA Internal Medicine. 2020;180(6):819-20.

5. Rejeh $\mathrm{N}$, Heravl-Karimooi $\mathrm{M}$, Montazeri $\mathrm{A}$, Foroughan $\mathrm{M}$, Vaismoradi M. Psychometric properties of the Iranian version of the Kogan's attitudes toward older people scale. Japan Journal of Nursing Science. 2012;9(2):216-22.

6. AGE Platform Europe. COVID-19: Older persons' rights must be equally protected during the pandemic 2020 [Available from: https://www.ageplatform.eu/policy-work/news/covid-19-older-persons\%E2\%80\%99rights-must-be-equally-protected-during-pandemic.

7. Nooritajer M, Hossein R, Haidari S. Models and systems of elderly care: factors associated with abuse in the elderly. Middle East J Age Ageing. 2011;83(2263):1-10.

8. Chang E-S, Kannoth S, Levy S, Wang S-Y, Lee JE, Levy BR. Global reach of ageism on older persons' health: A systematic review. PloS one. 2020;15(1):e0220857.

9. Mohammadi MM, Esmaeilivand M. Attitudes toward caring of the elderly from the perspective of nursing and midwifery students in Kermanshah Province in 2015. Iranian Journal of Ageing. 2017;11(4):476-83.

10. Morrow-Howell N, Galucia N, Swinford E. Recovering from the COVID-19 pandemic: A focus on older adults.J Aging Soc Policy. 2020 Jul-Oct; 32(45):526-35. Epub 2020 Apr 26. DOI: 10.1080/08959420.2020.1759758

\section{Ethics for laboratory professionals during the Covid pandemic}

Published online on May 28, 2020. DOI:10.20529/IJME.2020.063.

Keywords: laboratory medicine ethics, Covid-19, quarantine,corona heroes, microbiologists

It is not wrong to say that ethical issues have been given limited attention by professionals in laboratory medicine as compared to other fields of medicine (1). The most ethically problematic laboratory examinations are those dealing with genetic testing, autopsies, prenatal and HIV examinations and 